\title{
Validation of an FFQ for evaluation of EPA and DHA intake
}

\author{
Michel Lucas ${ }^{1, *}$, Geneviève Asselin ${ }^{1}$, Chantal Mérette ${ }^{2}$, Marie-Josée Poulin $^{2}$ and \\ Sylvie Dodin ${ }^{1,3}$ \\ ${ }^{1}$ Lucie and André Chagnon Chair for the Teaching of an Integrated Approach in Prevention, Laval University, \\ Saint-François d'Assise Hospital (CHUQ), 45 Leclerc Street, Room D6-701, Québec, Québec, Canada, G1L \\ 2G1: ${ }^{2}$ Department of Psychiatry, Robert Giffard Research Centre, Laval University, Québec, Québec, Canada: \\ ${ }^{3}$ Department of Obstetrics and Gynaecology, Laval University, Québec, Québec, Canada
}

Submitted 25 July 2008: Accepted 5 November 2008: First published online 23 December 2008

\begin{abstract}
Objective: To validate an FFQ for the assessment of dietary EPA and DHA against their relative concentrations in red blood cells (RBC).

Design: Cross-sectional analysis of baseline data. Intakes of marine food products and EPA and DHA were estimated by FFQ on the basis of consumption of marine food products in the last month. Fatty acid composition of RBC membranes was quantified by GC.

Setting: Saint-François d'Assise Hospital, Québec, Canada.

Subjects: A total of sixty-five middle-aged women who participated in a randomized clinical trial.

Results: Spearman's correlation coefficient between intake of EPA, DHA and EPA + DHA and their corresponding concentration in RBC was $0.46,0.40$ and 0.42 , respectively (all $P<0 \cdot 05$ ). Multiple regression analysis of EPA + DHA intake and RBC $\mathrm{EPA}+\mathrm{DHA}$ concentration indicated positive and significant correlations for oily fish $(\beta=0 \cdot 44,95 \%$ CI $0 \cdot 16,0 \cdot 72, P=0 \cdot 0027)$, total fish $(\beta=0 \cdot 42,95 \%$ CI $0 \cdot 19,0 \cdot 64$, $P=0 \cdot 0005)$ and marine food products $(\beta=0 \cdot 42,95 \%$ CI $0 \cdot 20,0 \cdot 64, P=0 \cdot 0003)$. No other marine food products significantly predicted RBC EPA + DHA concentration. Conclusions: Although the present validation study was undertaken among middleaged women with low consumption of marine food products $(<3$ servings/week), our FFQ provided estimates of EPA and DHA intakes that correlated fairly well with their RBC concentrations. However, the absence of correlations between EPA + DHA intakes from different marine species suggests that a minimum EPA + DHA intake is necessary to observe a relationship with RBC EPA + DHA concentrations.
\end{abstract}

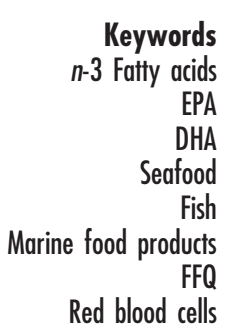

In nutrition research and clinical settings, short FFQ are powerful tools for estimating dietary exposures of interest and assessing the associated risks. There is emerging interest in the potential health benefits of marine product intake, with evidence of a protective role in $\mathrm{CVD}^{(1)}$, depression $^{(2)}$ and inflammatory disorders such as rheumatoid arthritis ${ }^{(3)}$. Two long-chain (LC) $n$-3 (omega-3) PUFA - EPA (20:5n-3) and DHA (22:6n-3) - have been proposed as being responsible for the beneficial effects of marine food products intake ${ }^{(4)}$. The measurement of nutritional biomarkers such as fatty acids (FA) in blood (plasma, red blood cells (RBC), etc.) offers a validation tool that has some advantages ${ }^{(5)}$. Such biomarkers of FA intake provide quantitative measurements independently of memory and/or knowledge of the subjects and are less likely to be due to social desirability bias and errors in completion than dietary self-reporting ${ }^{(6-9)}$.

Since LC $n$-3 PUFA cannot be synthesized de novo in the human body, they are known as essential FA and must come from the diet ${ }^{(10)}$. Therefore, $n$-3 represent ideal FA for validation $^{(7)}$. Although man is technically capable of endogenously synthesizing EPA and DHA from the $n$-3 precursor $\alpha$-linolenic acid ( $\alpha$-LNA, 18:3n-3) found in plants, this conversion is very limited ${ }^{(11)}$. Therefore, in general, EPA and DHA concentrations in blood reflect habitual dietary $n$ - 3 FA intake from fish ${ }^{(5)}$. For this reason, several studies have used EPA and DHA biomarkers to validate dietary EPA and DHA intake measured by $\mathrm{FFQ}^{(12-19)}$ and dietary records ${ }^{(20-22)}$. The present manuscript evaluates the validity of a simple FFQ for the assessment of dietary EPA and DHA against their relative concentrations in $\mathrm{RBC}$.

\section{Methods}

\section{Subjects}

Baseline data of middle-aged women involved in a clinical trial were taken for validation of our FFQ. This randomized 
clinical trial has been described in detail elsewhere ${ }^{(23)}$. Briefly, its aim was to compare the effects of enriched ethyl-EPA supplementation with placebo for the treatment of psychological distress and depressive symptoms. Women with low marine food product intakes $(<3$ servings/week) were recruited from the general population and were considered for participation if they were between 40 and 55 years of age and had moderate to severe psychological distress, defined as a score of $\leq 72$ on the Psychological General Well-Being Schedule ${ }^{(24)}$. Exclusion criteria were: past or current history of schizophrenia or bipolar I and II disorders; current or significant imminent risk of suicide or homicide; being postmenopausal for more than 5 years; endocrine diseases and medical disorders known to affect mental health; current substance abuse or dependence; fish allergies; taking antidepressants, hormone replacement therapy, St. John's wort (Hypericum perforatum) or fish oil supplements in the last 3 months before enrolment; and the use of anticoagulants.

A total of 120 women were randomized and allocated to treatments. It has been postulated that $n-3$ FA deficiency among major depressed people could be due to genetically impaired FA and phospholipid metabolism ${ }^{(25,26)}$. Therefore, we excluded from the present FFQ analysis women who had a baseline diagnosis of major depression episodes ( $n$ 29), minor depression ( $n$ 15) or dysthemia ( $n$ 2) according to criteria of the Diagnostic and Statistical Manual of Mental Disorders, fourth edition. Moreover, nine women had missing RBC FA measurement. The final sample size analysed was sixty-five.

\section{Design and procedures}

Interviews and questionnaires were administered at the Centre Menopause Québec of Saint-François d'Assise Hospital. All women signed an informed consent form after a full review of the inclusion and exclusion criteria and the risks and benefits of the study, which was approved by the Saint-François d'Assise Hospital Ethics and Clinical Research Board. A full medical history and semi-structured psychiatric evaluation were undertaken by clinic psychiatrists.

\section{The FFQ}

The FFQ had two principal questions. The first question referred to the portion size of fish consumed: 'In general, what is the portion size that corresponds best to your habitual consumption when you eat fish?' Each response had six predefined categories: ' $85 \mathrm{~g}$ ( $3 \mathrm{oz}$ ), i.e. a size equivalent to a regular deck of playing cards'; ' $113 \mathrm{~g}$ ( $4 \mathrm{oz}$ ), i.e. about $1 \frac{1}{2}$ times the size of a deck of cards'; ' $170 \mathrm{~g}$ ( $6 \mathrm{oz})$, i.e. 2 times the size of a deck of cards'; ' $227 \mathrm{~g}$ ( 8 oz), i.e. about $2 \frac{1}{2}$ times the size of a deck of cards'; 'never eat marine food products'; or 'don't know/refuse to answer'. The latter two categories were not offered to respondents but were noted if they provided these answers. A fixed portion of $85 \mathrm{~g}$ or $3 \mathrm{oz}$ was assigned for molluscs, crustaceans and imitation crab. The second question of the FFQ was aimed at knowing the frequency of marine food products consumed: 'Based on your food consumption of the last month, how many times did you consume the following marine food products?' Each response had eight pre-defined categories: 'never', 'once a month', '2-3 times per month', 'once a week', '2-3 times per week', ‘4-6 times per week', 'once a day' or 'don't know/refuse to answer'. These categories were converted to daily consumption frequency as follows: never $=0$, once a month $=1 / 30 \cdot 42,2-3$ times per month $=2 \cdot 5$ / $30 \cdot 42$, once a week $=1 / 7,2-3$ times per week $=2 \cdot 5 / 7$, 4-6 times per week $=5 / 7$ and once a day $=1$. The questionnaire included seven groups of marine food products: (i) oily fish (fresh or canned salmon, herring, mackerel, sardines); (ii) canned tuna; (iii) trout or halibut; (iv) white fish (sole, rockfish, haddock, cod, etc.); (v) molluscs (mussels, oysters, clams, scallops); (vi) crustaceans (shrimps, crabs, lobsters, etc.); and (vii) imitation crab. Based on the 2005 Canadian Nutrient File of Health Canada ${ }^{(27)}$ (see Appendix), each of these groups of marine food products was assigned an amount of $\mathrm{EPA}+$ DHA: $14 \cdot 9,3 \cdot 8,9 \cdot 3,3 \cdot 4,4 \cdot 9,2 \cdot 9$ and $6 \cdot 1 \mathrm{mg} / \mathrm{g}$, respectively. An amount of EPA was also assigned to each of these groups: $5 \cdot 9,0 \cdot 9,3 \cdot 7,1 \cdot 3,2 \cdot 4,1 \cdot 9$ and $2 \cdot 4 \mathrm{mg} / \mathrm{g}$, respectively. For DHA, amounts assigned to each group were respectively $9 \cdot 1,2 \cdot 8,5 \cdot 7,2 \cdot 1,2 \cdot 5,1 \cdot 1$ and $3 \cdot 6 \mathrm{mg} / \mathrm{g}$. The daily intake of each marine food product $(\mathrm{g} / \mathrm{d})$ was calculated by multiplying portion size $(\mathrm{g})$ by the frequency of consumption (per d). Thereafter, the daily intakes of EPA and DHA $(\mathrm{mg} / \mathrm{d})$ were calculated by multiplying the intake of each marine food product $(\mathrm{g} / \mathrm{d})$ by its EPA and DHA concentration $(\mathrm{mg} / \mathrm{g})$. Since docosapentaenoic acid (DPA, $22: 5 n$-3) measurement was not available from the FA profile of most fish and seafood in the Canadian Nutrient Data File, we were not able to determine DPA concentration in food products assessed by our FFQ.

\section{Determination of red blood cell fatty acid concentrations}

The FA composition of RBC membranes was quantified by GC (Lipid Research Centre, Laval University Research Centre (CHUQ)). RBC $(300 \mu \mathrm{l})$ were thawed and lysed in $1 \mathrm{ml}$ of water. The membranes were then isolated by centrifugation (21000 g, $15 \mathrm{~min}$ ) and washed twice with $0.9 \% \mathrm{NaCl}$ solution. The pellet was spiked with phosphatidylcholine C:15 (Avanti Polar Lipids, Alabaster, AL, USA) as internal standard. Lipids were extracted with a mixture of chloroform-methanol $(2: 1 \mathrm{v} / \mathrm{v})$ according to a modified Folch $\operatorname{method}^{(28)}$. Phospholipid FA were methylated ${ }^{(29)}$, and FA profiles were obtained by capillary GC on the temperature gradient of an HP5890 gas chromatograph (Hewlett Packard, Toronto, ON, Canada) equipped with an HP-88 capillary column $(100 \mathrm{~m} \times 0.25 \mathrm{~mm}$ internal diameter $\times 0.20 \mu \mathrm{m}$ 
film thickness; Agilent Technologies, Santa Clara, CA, USA) coupled with a flame ionization detector. The results are expressed as percentage of total FA. Only $n-6$ (omega-6) and $n-3$ PUFA concentrations are reported for the present purpose.

\section{Statistical analysis}

Given the small sample size and that most variables had a non-normal distribution, non-parametric tests were preferred. Arithmetic means were also calculated to facilitate comparisons with other studies. Spearman's partial correlation coefficient was used to determine the correlations between $n$ - 3 intakes and RBC concentrations. The KruskalWallis non-parametric ANOVA test was performed to compare RBC FA (\% total FA), marine food product $(\mathrm{g} / \mathrm{d}$ ) and EPA + DHA $(\mathrm{mg} / \mathrm{d})$ intakes according to tertile of total marine food products intake $(\mathrm{g} / \mathrm{d})$. Multiple linear regression analysis was undertaken to determine the relationship between EPA + DHA intake $(100 \mathrm{mg} / \mathrm{d})$ and $\mathrm{EPA}+\mathrm{DHA}$ in RBC (dependent variable). Because elongation of EPA to DHA and retroconversion of DHA to EPA are known mechanisms, EPA + DHA concentration in $\mathrm{RBC}$ was preferred as a dependent variable ${ }^{(30)}$. Moreover, it has been proposed that EPA + DHA concentration in $\mathrm{RBC}$ may be a better independent variable to assess the health effects of $n-3$ consumption from fish ${ }^{(31)}$. Covariables were selected without the predictor of interest in the multivariate model and were based on backward selection, considering a liberal $P$ value criterion of 0.5 for all relevant covariates ${ }^{(32)}$. The final models satisfied collinearity criteria. Statistical analyses were undertaken with the SAS for Windows statistical software package version 9 (SAS Institute, Inc., Cary, NC, USA). Differences between groups and associations were considered significant at $P \leq 0.05$ (bilateral).

\section{Results}

Baseline characteristics of the study participants are shown in Table 1. As expected, women included in the present validation study had less severe depression, psychological distress and vasomotor symptoms, with better quality of life scores, than those excluded. The other statistically different characteristics in the women included, compared with those excluded, were a higher married/cohabiting rate and superior intakes of total marine food products and EPA + DHA.

Intakes of marine food products, EPA and DHA by the study participants are shown in Table 2 . Total marine food products intake was $27 \cdot 6 \mathrm{~g} / \mathrm{d}$. EPA, DHA and EPA + DHA intakes were respectively $85 \cdot 4,128$ and $212 \mathrm{mg} / \mathrm{d}$. Spearman's correlation coefficient $\left(r_{\mathrm{s}}\right)$ between EPA, DHA and $\mathrm{EPA}+\mathrm{DHA}$ intakes and their corresponding concentrations in RBC was significant for total fish and marine food products (Table 3). The oily fish category was the only
Table 1 Baseline characteristics of the study participants: middleaged women ( $n 65)$ who participated in a randomized clinical trial, Québec, Canada

\begin{tabular}{|c|c|c|c|c|}
\hline & Mean & SD & $n$ & $\%$ \\
\hline \multicolumn{5}{|l|}{ Demographic } \\
\hline Age (years) & $48 \cdot 3$ & $3 \cdot 8$ & & \\
\hline Married/cohabiting & & & 46 & $70 \cdot 8$ \\
\hline Employed outside the home & & & 58 & $89 \cdot 2$ \\
\hline College education or more & & & 52 & $80 \cdot 0$ \\
\hline BMI $\left(\mathrm{kg} / \mathrm{m}^{2}\right)$ & $25 \cdot 0$ & $4 \cdot 3$ & & \\
\hline Waist circumference (cm) & $82 \cdot 1$ & $10 \cdot 0$ & & \\
\hline \multicolumn{5}{|l|}{ Lifestyle } \\
\hline Active ( $\geq 3$ times/week) & & & 31 & $47 \cdot 7$ \\
\hline Current smokers & & & 12 & $18 \cdot 8$ \\
\hline No. of cigarette/d among smokers & $10 \cdot 8$ & $8 \cdot 2$ & & \\
\hline Alcohol (no. of drinks/week) & $3 \cdot 7$ & $4 \cdot 2$ & & \\
\hline \multicolumn{5}{|l|}{ Menopausal and psychiatric } \\
\hline Menopausal status & & & 17 & $26 \cdot 2$ \\
\hline Time since menopause (years) & $2 \cdot 7$ & $1 \cdot 5$ & & \\
\hline Prior hormone therapy & & & 9 & $13 \cdot 9$ \\
\hline PGWB score & 59 & 10 & & \\
\hline History of PMS & & & 9 & $13 \cdot 9$ \\
\hline History of MDE & & & 25 & $38 \cdot 5$ \\
\hline
\end{tabular}

PGWB, Psychological General Well-Being Schedule; PMS, premenstrual syndrome; MDE, major depressive episode.

individual marine group that was significantly correlated. The highest correlations noted were for total marine food products, and the results were 0.46 for RBC EPA, 0.40 for RBC DHA and 0.42 for RBC EPA + DHA. According to the lowest to the highest tertile of total marine food products intake, EPA and DHA content in RBC increased progressively, whereas there were no such correlations for $\alpha$-LNA and DPA (Table 4). Also, no differences in RBC $n-6$ were noted according to tertile of total marine food products intake. EPA + DHA intake from oily fish, total fish and marine food products increased across tertile of total marine food products intake. Mean estimated total EPA + DHA intake $(\mathrm{mg} / \mathrm{d}$ ) was $77 \cdot 0$ (SD 47.7) for the first, 174 (SD 83.8) for the second and 379 (SD 154) for the third tertile.

The results of multiple regression analysis of EPA + DHA intake from marine food products $v$. RBC EPA + DHA concentration are shown in Table 5. Positive and significant correlations were noted for oily fish, total fish and marine food products. No other marine food products significantly predicted EPA + DHA concentration. The contribution of EPA + DHA intake from oily fish, total fish and marine food products to the predicted EPA + DHA concentration was 15\%, 19\% and $21 \%$, respectively.

\section{Discussion}

In the present study, we noted that estimations of $\mathrm{EPA}+\mathrm{DHA}$ intake from our FFQ were reflected in RBC concentrations. Significant correlations were observed in RBC for oily fish, total fish and marine food products. Multiple linear regression analysis indicated that RBC $\mathrm{EPA}+\mathrm{DHA}$ concentration increased by $0.42 \%$ with each dietary intake increment of $100 \mathrm{mg} \mathrm{EPA}+\mathrm{DHA} / \mathrm{d}$. 
Table 3 Spearman's correlation coefficient $\left(r_{\mathrm{s}}\right)$ between RBC EPA, DHA and EPA + DHA concentrations and their corresponding dietary intakes: middle-aged women ( $n$ 65), Québec, Canada

\begin{tabular}{|c|c|c|c|}
\hline & \multicolumn{3}{|c|}{ RBC $n-3$ FA ( $\%$ of total FA) } \\
\hline & EPA & DHA & $\mathrm{EPA}+\mathrm{DHA}$ \\
\hline \multicolumn{4}{|l|}{$n$-3 FA intake $(\mathrm{mg} / \mathrm{d})$ from } \\
\hline Oily fish & $0 \cdot 40^{\star}$ & $0.37^{\star}$ & $0.38^{*}$ \\
\hline Canned tuna & $0 \cdot 11$ & $0 \cdot 17$ & $0 \cdot 16$ \\
\hline Trout and halibut & 0.08 & 0.15 & $0 \cdot 15$ \\
\hline White fish & 0.21 & $0 \cdot 12$ & $0 \cdot 15$ \\
\hline Total fish & $0 \cdot 38^{*}$ & $0 \cdot 36^{*}$ & $0.37^{\star}$ \\
\hline Molluscs & $0 \cdot 10$ & $0 \cdot 17$ & $0 \cdot 16$ \\
\hline Crustaceans & $0 \cdot 22$ & 0.21 & 0.24 \\
\hline Imitation crab & $0.25^{\star}$ & $0 \cdot 14$ & $0 \cdot 16$ \\
\hline Total marine food products & $0.46^{*}$ & $0 \cdot 40^{*}$ & $0.42^{*}$ \\
\hline
\end{tabular}

RBC, red blood cell: FA, fatty acids.

Correlation was significant: ${ }^{\star} P<0 \cdot 05$.

We discerned that Spearman's partial correlation coefficients between RBC FA concentrations and their corresponding dietary intakes were $0 \cdot 46$ for EPA, $0 \cdot 40$ for DHA and 0.42 for EPA + DHA. Other studies that evaluated the relationship between $\mathrm{RBC}$ concentrations of EPA and DHA and their dietary intakes reported correlation coefficients ranging from $0 \cdot 21$ to 0.55 for EPA and from $0 \cdot 35$ to 0.58 for $\mathrm{DHA}^{(12,33-37)}$. Among 306 women from the Nurses' Health Survey aged 43-69 years, correlation coefficients between FA intake measured by FFQ in 1990 and RBC FA composition measured in 1990 were $0 \cdot 38$ for EPA and 0.56 for DHA ${ }^{(12)}$. In a cross-sectional analysis of premenopausal ( $n$ 93) and postmenopausal ( $n$ 104) women aged 39-65 years drawn from the ORDET cohort in Italy, Fuhrman et al. established that correlation coefficients between RBC concentration and dietary FA intake from an FFQ were respectively $0 \cdot 21$ and $0 \cdot 41$ for EPA and 0.43 and 0.44 for $\mathrm{DHA}^{(36)}$. Even if correlations between plasma phospholipid and RBC DHA and EPA concentrations are strong ${ }^{(12,38)}$, it is difficult to directly compare our results with those of studies that used plasma phospholipid measurements. However, it is likely that our correlations might be higher for plasma because our FFQ queries intakes in the last month. Indeed, according to the 18-month controlled study of Katan et al., half maximal and maximal concentrations for EPA in RBC are reached after 28 and $180 \mathrm{~d}$, respectively ${ }^{(39)}$. However, these stages were attained after 4.8 and $56 \mathrm{~d}$ for serum cholesteryl esters, indicating that $\mathrm{RBC}$ might reflect more long-term intake than plasma or serum.

Except for the oily fish category in our FFQ, we did not observe any significant correlation between RBC EPA + DHA concentration and dietary EPA + DHA contribution of other marine species. The importance of the relationship between EPA + DHA intake from marine species and RBC EPA + DHA concentrations seems to be related to the relative contributions to daily EPA + DHA intakes. Indeed, fatty fish contributed $60 \%$ of the total estimated intake of $212 \mathrm{mg} \mathrm{EPA}+\mathrm{DHA} / \mathrm{d}$, whereas canned tuna, 
Table 4 RBC FA concentrations and intakes of marine food products and EPA + DHA according to tertile of total marine food products intake: middle-aged women ( $n$ 65), Québec, Canada

\begin{tabular}{|c|c|c|c|c|c|c|c|}
\hline & \multicolumn{6}{|c|}{ Tertile of total marine food products intake $(\mathrm{g} / \mathrm{d})$} & \multirow[b]{3}{*}{$P+$} \\
\hline & \multicolumn{2}{|c|}{$<16 \cdot 8(n 21)$} & \multicolumn{2}{|c|}{$16 \cdot 8-32 \cdot 6(n 22)$} & \multicolumn{2}{|c|}{$\geq 32 \cdot 7(n 22)$} & \\
\hline & Median & Min, $\max$ & Median & Min, $\max$ & Median & Min, $\max$ & \\
\hline \multicolumn{8}{|l|}{ RBC FA ( $\%$ of total FA) } \\
\hline Total $n-6$ & $27 \cdot 0$ & $11 \cdot 1,30 \cdot 5$ & $27 \cdot 2$ & $14 \cdot 2,30 \cdot 1$ & $27 \cdot 3$ & $15 \cdot 7,30 \cdot 0$ & $0 \cdot 8047$ \\
\hline LA & $9 \cdot 51$ & $6 \cdot 14,12 \cdot 2$ & $9 \cdot 99$ & $7 \cdot 57,12 \cdot 5$ & $9 \cdot 47$ & $7 \cdot 33,11 \cdot 2$ & 0.7236 \\
\hline $\mathrm{AA}$ & $12 \cdot 2$ & $3 \cdot 26,16 \cdot 2$ & $12 \cdot 8$ & $4 \cdot 58,14 \cdot 9$ & $12 \cdot 8$ & $5 \cdot 06,15 \cdot 4$ & 0.8434 \\
\hline Total $n-3$ & $5 \cdot 80$ & $1 \cdot 49,9 \cdot 34$ & $7 \cdot 54$ & $2 \cdot 92,9 \cdot 26$ & $7 \cdot 81$ & $1 \cdot 33,11 \cdot 5$ & 0.0046 \\
\hline$\alpha$-LNA & $0 \cdot 19$ & $0,0.35$ & $0 \cdot 18$ & $0,0 \cdot 33$ & $0 \cdot 20$ & $0,0.29$ & 0.4774 \\
\hline EPA & 0.61 & $0 \cdot 18,1 \cdot 16$ & $0 \cdot 86$ & $0.33,1.26$ & 0.99 & $0 \cdot 22,2 \cdot 21$ & 0.0002 \\
\hline DPA & $1 \cdot 86$ & $0.23,2.94$ & $2 \cdot 33$ & $0.70,2 \cdot 97$ & $2 \cdot 25$ & $0 \cdot 43,2 \cdot 78$ & $0 \cdot 1004$ \\
\hline DHA & $2 \cdot 84$ & $0.29,4.72$ & $3 \cdot 73$ & $1 \cdot 29,5 \cdot 25$ & $4 \cdot 27$ & $0 \cdot 67,6 \cdot 11$ & 0.0019 \\
\hline Sum EPA + DHA & $3 \cdot 43$ & $0 \cdot 47,5 \cdot 73$ & $4 \cdot 50$ & $1 \cdot 62,6 \cdot 21$ & $5 \cdot 26$ & $0.90,8.32$ & 0.0009 \\
\hline Sum EPA + DPA + DHA & $5 \cdot 32$ & $0.82,8.66$ & $6 \cdot 93$ & $2 \cdot 57,8.69$ & $7 \cdot 46$ & $1 \cdot 33,11 \cdot 0$ & 0.0031 \\
\hline \multicolumn{8}{|l|}{ Marine food product intake $(\mathrm{g} / \mathrm{d})$} \\
\hline Oily fish & $2 \cdot 79$ & $0,12 \cdot 1$ & $6 \cdot 98$ & $0,30 \cdot 4$ & $12 \cdot 1$ & $0,30 \cdot 4$ & $<0.0001$ \\
\hline Total fish & $6 \cdot 99$ & $0,14.9$ & $19 \cdot 1$ & $5 \cdot 59,30 \cdot 4$ & $30 \cdot 6$ & $9 \cdot 78,72 \cdot 9$ & $<0.0001$ \\
\hline Total marine food products & $11 \cdot 2$ & $0,15 \cdot 4$ & $23 \cdot 0$ & $16 \cdot 8,31 \cdot 7$ & $41 \cdot 3$ & $32 \cdot 7,99 \cdot 9$ & $<0.0001$ \\
\hline \multicolumn{8}{|c|}{ Estimated EPA + DHA intake $(\mathrm{mg} / \mathrm{d})$ from } \\
\hline Oily fish & $41 \cdot 6$ & 0,181 & 104 & 0,452 & 181 & 0,452 & $<0.0001$ \\
\hline Total fish & $67 \cdot 6$ & 0,190 & 150 & $23 \cdot 8,452$ & 279 & 115,653 & $<0.0001$ \\
\hline Total marine food products & $76 \cdot 3$ & 0,190 & 162 & $74 \cdot 9,452$ & 301 & 203,758 & $<0.0001$ \\
\hline
\end{tabular}

RBC, red blood cell; FA, fatty acids; Total $n-6$, sum of $n-6(18: 2+18: 3+20: 2+20: 3+20: 4+22: 2+22: 4+22: 5) ;$ LA, linoleic acid (18:2n-6); AA, arachidonic acid $(20: 4 n-6)$; Total $n-3$, sum of $n-3(18: 3+18: 4+20: 3+20: 4+20: 5+22: 5+22: 6) ; \alpha-L N A, \alpha-$ linolenic acid (18:3n-3); EPA, 20:5n-3; DHA, 22:6n-3; DPA, docosapentaenoic acid $(22: 5 n-3)$.

tSignificance of non-parametric ANOVA, $P<0.05$ (Kruskal-Wallis test).

Table 5 Linear multiple regression analysis of EPA + DHA intake $(100 \mathrm{mg} / \mathrm{d})$ from marine food products and RBC EPA + DHA concentration (\% of total FA) as dependent variable: middle-aged women ( $n 65)$, Québec, Canadat

\begin{tabular}{|c|c|c|c|c|c|c|}
\hline & \multicolumn{4}{|c|}{ Independent variable } & \multicolumn{2}{|c|}{ Modelt } \\
\hline & $\beta$ & $95 \% \mathrm{Cl}$ & Partial $R^{2}$ & $P \ddagger$ & $R^{2}$ & $P \S$ \\
\hline \multicolumn{7}{|l|}{ Marine food products $(100 \mathrm{mg} / \mathrm{d})$} \\
\hline Oily fish & 0.44 & $0 \cdot 16,0 \cdot 72$ & 0.15 & 0.0027 & 0.36 & 0.0009 \\
\hline Total fish & 0.42 & $0.19,0.64$ & 0.19 & 0.0005 & 0.40 & 0.0002 \\
\hline Total marine food products & 0.42 & $0.20,0.64$ & 0.21 & 0.0003 & 0.41 & 0.0001 \\
\hline
\end{tabular}

RBC, red blood cell.

tModels adjusted for age, alcohol, employed outside the home, active, history of major depressive episode, prior hormone therapy, Psychological General Well-Being Schedule score.

$\ddagger$ Significance of the marine food product.

$\S$ Significance of the general regression model.

trout and halibut, and white fish contributed $8 \%$, $11 \%$ and $7 \%$, respectively. Among 234 middle-aged Norwegian women, no significant correlation was noted between lean fish intake and serum phospholipid EPA or $\mathrm{DHA}^{(15)}$. In a dietary intervention with enriched $n-3$ foods ( $\sim 125 \mathrm{mg}$ of very LC $n$-3 PUFA per serving) among overweight volunteers consuming less than 1 serving of fish per week, Patch et al. found that measurement of very LC $n$-3 PUFA after 6 months reflected habitual intakes ${ }^{(35)}$. However, no significant correlation was noted among individuals with consumption rates lower than $200 \mathrm{mg} / \mathrm{d}$.

In our study, correlations were slightly superior for EPA compared with DHA. RBC EPA concentration has been suggested to be a better marker of fish and fish oil intake than RBC $\mathrm{DHA}^{(40)}$. This might be explained by the fact that EPA measurement in blood appears to be less saturable than $\mathrm{DHA}^{(38,40)}$. Brown et al. ${ }^{(41)}$ suggested that DHA turnover in RBC is slower than that of EPA. However, others have reported stronger correlations between fish intake and plasma DHA than EPA ${ }^{(16,17)}$. Nevertheless, it has been postulated that the combination of RBC EPA and DHA may be a better independent variable to assess the health effects of $n-3$ PUFA consumption from fish ${ }^{(31)}$. Indeed, RBC EPA + DHA correlates very well with the risk of death from $\mathrm{CHD}^{(31)}$ and $n-3$ concentration in human myocardial tissue ${ }^{(42)}$. Moreover, elongation of EPA to DHA and retroconversion of DHA to EPA are known mechanisms ${ }^{(30)}$. Therefore, it is scientifically logical to use $\mathrm{EPA}+\mathrm{DHA}$ as a biomarker of these FA.

The fact that full diet composition was not estimated by our FFQ represents a major limitation of the present 
validation study. Indeed, we were unable to evaluate the energy-adjusted effect of EPA/DHA as proposed by Willett $^{(7)}$. We also did not measure the intake of the $n-3$ PUFA consumed most frequently by North Americans, $\alpha$-LNA. However, in vivo studies among human subjects with $\alpha$-LNA tracer showed that $5 \%$ of $\alpha$-LNA is converted to EPA and $<0.5 \%$ to $\mathrm{DHA}^{(11)}$. Therefore, intakes of $\alpha$-LNA might not interfere in an important way in the relationship between EPA + DHA intakes estimated by the FFQ and RBC EPA + DHA concentrations. The fact that the present FFQ was validated among women only might represent another limitation and constrain external validity. However, conversion of $\alpha$-LNA to EPA or DHA has been suggested to be higher among young women due to oestrogen ${ }^{(43)}$. Nevertheless, if this also applies to middle-aged women, higher conversion could have reduced the relationship between $\mathrm{RBC}$ EPA + DHA concentration and its dietary intake. Moreover, if the $\alpha$-LNA conversion rate is likely higher among women than men, the relationship between EPA + DHA intake and RBC $\mathrm{EPA}+\mathrm{DHA}$ concentration might be at least equal or superior to that in men.

It seems unrealistic to observe a nearly perfect correlation of RBC EPA + DHA concentration with its dietary intake with any food assessment tool. Individuals with similar EPA and DHA intakes may not have similar EPA and DHA concentrations in $\mathrm{RBC}^{(37,44)}$. This might be explained by several factors, such as absorption, tissue turnover, temporal correlation with dietary intake and genes-food-environment interaction ${ }^{(45)}$. Moreover, the relationship with biomarkers might be biased by many limitations of the dietary assessment tool, such as memory, capacity to describe food, average intake over a period of time, errors in completion and social desirability ${ }^{(45)}$. In addition, nutrient databases may not adequately reflect temporal changes in food composition ${ }^{(8)}$. Even if biomarkers provide more accurate objective measures that are less susceptible to error than dietary intake estimates, measurement errors are possible ${ }^{(5)}$. As suggested by Arab, interpretation of FA concentration ( $\%$ of total FA) instead of absolute amount $(\mathrm{md} / \mathrm{dl})$ might alter the relationship between estimated dietary intake and biomarkers ${ }^{(5)}$. Indeed, all FA are linked when percentages are used. Greater intake of a specific FA might drive down the relative percentage of other FA, even if their intakes are unaltered. Unknown and non-determined disease might also have an effect on FA profiles. In the present study, ill women were excluded, and we restricted our analysis to females without major depression episodes, minor depression and dysthemia.

In conclusion, although the present validation study was conducted among middle-aged women with low consumption of marine food products $(<3$ servings/ week), our simple FFQ provided estimates of EPA and DHA intakes that correlated fairly well with their RBC concentrations.

\section{Acknowledgements}

Except M.L., who received speaking honoraria and travel expenses from Isodis Natura, no other author had any financial or conflict of interest related to the present manuscript. The work was supported by the Lucie and André Chagnon Chair for the Teaching of an Integrated Approach in Prevention, Laval University. The omega-3 capsules and matching placebo for the randomized clinical study were provided by Isodis Natura (Brussels, Belgium). The contributions of each author in this work were as follows. Study concept and design: M.L., S.D., C.M., M.-J.P., G.A.; analysis of the data: M.L., S.D., C.M.; interpretation of the data: M.L., S.D., C.M., M.-J.P., G.A.; drafting the manuscript: M.L.; critical revision of the manuscript: M.L., S.D., C.M., M.-J.P., G.A. The authors express their gratitude to all study participants and acknowledge the contributions of their collaborators: Dr G. Roy, Dr Y. Lapierre, Dr T. Chamard-Bergeron, Dr S. Desautels, Dr D. Bélisle, Ms M. Longpré, Ms J. Pelletier, Dr C. Lajeunesse and Ms C. Émond. Trial Registration: International Standard Randomized Controlled Trial Number ISRCTN69617477 (http://www. controlled-trials.com).

\section{References}

1. Kris-Etherton PM, Harris WS \& Appel LJ (2002) AHA Scientific Statement. Fish consumption, fish oil, omega-3 fatty acids, and cardiovascular disease. Circulation 106, $2747-2757$.

2. Freeman MP, Hibbeln JR, Wisner KL et al. (2006) Omega-3 fatty acids: evidence basis for treatment and future research in psychiatry. J Clin Psychiatry 67, 1954-1967.

3. Calder PC (2006) n-3 Polyunsaturated fatty acids, inflammation, and inflammatory diseases. Am J Clin Nutr 83, 6 Suppl., 1505S-1519S.

4. Mozaffarian D \& Rimm EB (2006) Fish intake, contaminants, and human health: evaluating the risks and the benefits. JAMA 296, 1885-1899.

5. Arab L (2003) Biomarkers of fat and fatty acid intake. J Nutr 133, Suppl. 3, 925S-932S.

6. Bates CJ \& Thurnham DI (1997) Biochemical markers of nutrient intake. In Design Concepts in Nutritional Epidemiology, 2nd ed., pp. 170-240 [BM Margetts and $\mathrm{M}$ Nelson, editors]. New York: Oxford University Press.

7. Willett WC (editor) (1998) Nutritional Epidemiology, 2nd ed., p. 414. New York: Oxford University Press.

8. Cantwell MM (2000) Assessment of individual fatty acid intake. Proc Nutr Soc 59, 187-191.

9. Hebert JR, Ma Y, Clemow L, Ockene IS, Saperia G, Stanek EJ 3rd, Mérriam PA \& Ockene JK (1997) Gender differences in social desirability and social approval bias in dietary selfreport. Am J Epidemiol 146, 1046-1055.

10. Holman RT (1998) The slow discovery of the importance of omega 3 essential fatty acids in human health. J Nutr 128, 2 Suppl., 427S-433S.

11. Plourde M \& Cunnane S (2007) Extremely limited synthesis of long chain polyunsaturates in adults: implications for their dietary essentiality and use as supplements. Appl Physiol Nutr Metab 32, 619-634. 
12. Sun Q, Ma J, Campos H, Hankinson SE \& Hu FB (2007) Comparison between plasma and erythrocyte fatty acid content as biomarkers of fatty acid intake in US women. Am J Clin Nutr 86, 74-81.

13. Kobayashi M, Sasaki S, Kawabata T, Hasegawa K \& Tsugane S (2003) Validity of a self-administered food frequency questionnaire used in the 5-year follow-up survey of the JPHC Study Cohort I to assess fatty acid intake: comparison with dietary records and serum phospholipid level. J Epidemiol 13, 1 Suppl., S64-S81.

14. Barberger-Gateau P, Jutand MA, Letenneur L, Larrieu S, Tavernier B \& Berr C; 3C Study Group (2005) Correlates of regular fish consumption in French elderly community dwellers: data from the Three-City study. Eur J Clin Nutr 59, 817-825.

15. Hjartaker A, Lund E \& Bjerve KS (1997) Serum phospholipid fatty acid composition and habitual intake of marine foods registered by a semi-quantitative food frequency questionnaire. Eur J Clin Nutr 51, 736-742.

16. Woods RK, Stoney RM, Ireland PD, Bailey MJ, Raven JM, Thien FC, Walters EH \& Abramson MJ (2002) A valid food frequency questionnaire for measuring dietary fish intake. Asia Pac J Clin Nutr 11, 56-61.

17. Mina K, Fritschi L \& Knuiman M (2007) A valid semiquantitative food frequency questionnaire to measure fish consumption. Eur J Clin Nutr 61, 1023-1031.

18. Hodge AM, Simpson JA, Gibson RA, Sinclair AJ, Makrides M, O'Dea K, English DR \& Giles GG (2007) Plasma phospholipid fatty acid composition as a biomarker of habitual dietary fat intake in an ethnically diverse cohort. Nutr Metab Cardiovasc Dis 17, 415-426.

19. Baylin A, Kim MK, Donovan-Palmer A, Siles X, Dougherty L, Tocco P \& Campos H (2005) Fasting whole blood as a biomarker of essential fatty acid intake in epidemiologic studies: comparison with adipose tissue and plasma. $A m \mathrm{~J}$ Epidemiol 162, 373-381.

20. Broadfield E, McKeever T, Fogarty A \& Britton J (2003) Measuring dietary fatty acid intake: validation of a foodfrequency questionnaire against $7 \mathrm{~d}$ weighed records. Br J Nutr 90, 215-220.

21. Kobayashi M, Sasaki S, Kawabata T, Hasegawa K, Akabane M \& Tsugane S (2001) Single measurement of serum phospholipid fatty acid as a biomarker of specific fatty acid intake in middle-aged Japanese men. Eur J Clin Nutr 55, 643-650.

22. Kuriki K, Nagaya T, Tokudome $\mathrm{Y}$ et al. (2003) Plasma concentrations of $(n-3)$ highly unsaturated fatty acids are good biomarkers of relative dietary fatty acid intakes: a cross-sectional study. J Nutr 133, 3643-3650.

23. Lucas M, Asselin G, Mérette C, Poulin M-J \& Dodin S (2008) Ethyl-eicosapentaenoic acid in the treatment of psychological distress and depressive symptoms among middle-aged women: a double-blind, placebo-controlled, randomized clinical trial. Am J Clin Nutr (In the Press).

24. Dupuy H (1984) The Psychological General Well-Being (PGWB) Index. In Assessment of Quality of Life in Clinical Trials of Cardiovascular Therapies, pp. 170-183 [NK Wenger, ME Mattson, CD Furber et al., editors]. New York: Le Jacq Publishing Inc.

25. Ross BM (2007) Omega-3 fatty acid deficiency in major depressive disorder is caused by the interaction between diet and a genetically determined abnormality in phospholipid metabolism. Med Hypotheses 68, 515-524.

26. Horrobin DF \& Bennett CN (1999) Depression and bipolar disorder: relationships to impaired fatty acid and phospholipid metabolism and to diabetes, cardiovascular disease, immunological abnormalities, cancer, ageing and osteoporosis. Possible candidate genes. Prostaglandins Leukot Essent Fatty Acids 60, 217-234.
27. Health Canada (2005) Canadian Nutrient File. http:// www.hc-sc.gc.ca/fn-an/nutrition/fiche-nutri-data/index_e. html (accessed October 2006).

28. Shaikh NA \& Downar E (1981) Time course of changes in porcine myocardial phospholipid levels during ischemia. A reassessment of the lysolipid hypothesis. Circ Res $\mathbf{4 9}$, 316-325.

29. Lepage G \& Roy CC (1986) Direct transesterification of all classes of lipids in a one-step reaction. J Lipid Res 27, 114-120.

30. Sprecher H (2000) Metabolism of highly unsaturated $n-3$ and $n-6$ fatty acids. Biochim Biophys Acta 1486, 219-231.

31. Harris WS \& Von Schacky C (2004) The Omega-3 Index: a new risk factor for death from coronary heart disease? Prev Med 39, 212-220.

32. Babyak MA (2004) What you see may not be what you get: a brief, nontechnical introduction to overfitting in regression-type models. Psychosom Med 66, 411-421.

33. Godley PA, Campbell MK, Miller C, Gallagher P, Martinson FE, Mohler JL \& Sandler RS (1996) Correlation between biomarkers of omega-3 fatty acid consumption and questionnaire data in African American and Caucasian United States males with and without prostatic carcinoma. Cancer Epidemiol Biomarkers Prev 5, 115-119.

34. Parra MS, Schnaas L, Meydani M, Perroni E, Martinez S \& Romieu I (2002) Erythrocyte cell membrane phospholipid levels compared against reported dietary intakes of polyunsaturated fatty acids in pregnant Mexican women. Public Health Nutr 5, 931-937.

35. Patch C, Murphy K, Mansour J et al. (2004) Erythrocyte biomarker-based validation of a diet history method used in a dietary intervention trial. Asia Pac J Clin Nutr 13, Suppl., S60.

36. Fuhrman BJ, Barba M, Krogh V et al. (2006) Erythrocyte membrane phospholipid composition as a biomarker of dietary fat. Ann Nutr Metab 50, 95-102.

37. Cao J, Schwichtenberg KA, Hanson NQ \& Tsai MY (2006) Incorporation and clearance of omega-3 fatty acids in erythrocyte membranes and plasma phospholipids. Clin Chem 52, 2265-2272.

38. Arterburn LM, Hall EB \& Oken H (2006) Distribution, interconversion, and dose response of $n-3$ fatty acids in humans. Am J Clin Nutr 83, 6 Suppl., 1467S-1476S.

39. Katan MB, Deslypere JP, van Birgelen APJM, Penders M \& Zegwaard M (1997) Kinetics of the incorporation of dietary fatty acids into serum cholesteryl esters, erythrocyte membranes, and adipose tissue: an 18-month controlled study. J Lipid Res 38, 2012-2022.

40. Brown AJ, Pang E \& Roberts DCK (1991) Erythrocyte eicosapentaenoic acid versus docosahexaenoic acid as a marker for fish and fish oil consumption. Prostaglandins Leukot Essent Fatty Acids 44, 103-106.

41. Brown AJ, Pang E \& Roberts DC (1991) Persistent changes in the fatty acid composition of erythrocyte membranes after moderate intake of $n-3$ polyunsaturated fatty acids: study design implications. Am J Clin Nutr 54, 668-673.

42. Harris WS, Sands SA, Windsor SL, Ali HA, Stevens TL, Magalski A, Porter CB \& Borkon AM (2004) Omega-3 fatty acids in cardiac biopsies from heart transplantation patients: correlation with erythrocytes and response to supplementation. Circulation 110, 1645-1649.

43. Burdge $G$ (2004) $\alpha$-Linolenic acid metabolism in men and women: nutritional and biological implications. Curr Opin Clin Nutr Metab Care 7, 137-144.

44. Anderson LF, Solvoll K \& Drevon CA (1996) Verylong-chain $n-3$ fatty acids as biomarkers for intake of fish and $n-3$ fatty acid concentrates. Am J Clin Nutr 64, 305-311.

45. Potischman N (2003) Biologic and methodologic issues for nutritional biomarkers. J Nutr 133, Suppl. 3, 875S-880S. 
Appendix

Fatty acid composition of food products in the Marine Omega-3 Food Frequency Questionnaire (Marine

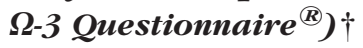

\begin{tabular}{|c|c|c|c|c|c|c|c|c|}
\hline Marine food group/food name & $\begin{array}{l}\text { Food } \\
\text { code }\end{array}$ & $\%$ Fat & $\begin{array}{c}\text { SFA } \\
(\mathrm{g} / 100 \mathrm{~g})\end{array}$ & $\begin{array}{l}\text { MUFA } \\
(\mathrm{g} / 100 \mathrm{~g})\end{array}$ & $\begin{array}{l}\text { PUFA } \\
(\mathrm{g} / 100 \mathrm{~g})\end{array}$ & $\begin{array}{c}\text { EPA } \\
(\mathrm{g} / 100 \mathrm{~g})\end{array}$ & $\begin{array}{c}\mathrm{DHA} \\
(\mathrm{g} / 100 \mathrm{~g})\end{array}$ & $\begin{array}{c}\mathrm{EPA}+\mathrm{DHA} \\
(\mathrm{g} / 100 \mathrm{~g})\end{array}$ \\
\hline $\begin{array}{l}\text { Oily fish (fresh or canned salmon, herring, mackerel, } \\
\text { sardines) }\end{array}$ & & & & & & 0.59 & 0.91 & $1 \cdot 49$ \\
\hline Salmon, Atlantic, farmed $\neq$ & 3183 & $12 \cdot 4$ & $2 \cdot 5$ & $4 \cdot 4$ & $4 \cdot 4$ & 0.69 & $1 \cdot 46$ & $2 \cdot 15$ \\
\hline Salmon, sockeye (red)§ & 3223 & $10 \cdot 1$ & $2 \cdot 3$ & $3 \cdot 2$ & 1.9 & 0.74 & $1 \cdot 11$ & $1 \cdot 85$ \\
\hline Salmon, pink (humpback) $\S$ & 3222 & $7 \cdot 4$ & $1 \cdot 7$ & $2 \cdot 7$ & $2 \cdot 6$ & $0 \cdot 61$ & $1 \cdot 08$ & $1 \cdot 69$ \\
\hline Tuna, bluefin $\ddagger$ & 3080 & $6 \cdot 3$ & $1 \cdot 6$ & $2 \cdot 1$ & $1 \cdot 8$ & 0.36 & $1 \cdot 14$ & 1.50 \\
\hline Herring, Atlantic, pickled & 3016 & $18 \cdot 0$ & $2 \cdot 4$ & $11 \cdot 9$ & $1 \cdot 7$ & $0 \cdot 84$ & 0.55 & $1 \cdot 39$ \\
\hline Mackerel, Atlantic & 3022 & $17 \cdot 8$ & $4 \cdot 2$ & $7 \cdot 0$ & $4 \cdot 3$ & 0.50 & $0 \cdot 70$ & $1 \cdot 20$ \\
\hline Salmon, chum (keta) $\S$ & 3218 & $5 \cdot 5$ & $1 \cdot 5$ & $1 \cdot 9$ & 1.5 & 0.47 & $0 \cdot 70$ & $1 \cdot 18$ \\
\hline Sardine, Atlantic $\S$ & 3203 & $11 \cdot 5$ & 1.5 & 3.9 & $5 \cdot 1$ & 0.47 & 0.51 & 0.98 \\
\hline Canned tuna & & & & & & 0.09 & 0.28 & 0.38 \\
\hline Tuna, white, with water§ & 3084 & $3 \cdot 0$ & $0 \cdot 8$ & $0 \cdot 8$ & $1 \cdot 1$ & 0.23 & 0.63 & $0 \cdot 86$ \\
\hline Tuna, light, with water§ & 3081 & $0 \cdot 8$ & $0 \cdot 2$ & $0 \cdot 2$ & $0 \cdot 3$ & 0.05 & $0 \cdot 22$ & $0 \cdot 27$ \\
\hline Tuna, white, with oil§ & 3083 & $8 \cdot 1$ & $1 \cdot 3$ & $3 \cdot \overline{3}$ & $3 \cdot 0$ & 0.07 & $0 \cdot 18$ & 0.24 \\
\hline Tuna, light, with oil§̧ & 3207 & $8 \cdot 2$ & $1 \cdot 5$ & $2 \cdot 9$ & $2 \cdot 9$ & 0.03 & $0 \cdot 10$ & $0 \cdot 13$ \\
\hline Trout and halibut & & & & & & 0.37 & 0.57 & 0.93 \\
\hline Trout, rainbow, farmedł & 3187 & $7 \cdot 2$ & $2 \cdot 1$ & $2 \cdot 1$ & $2 \cdot 3$ & 0.33 & $0 \cdot 82$ & $1 \cdot 15$ \\
\hline Halibut, Greenland (turbot) $\ddagger$ & 3143 & $17 \cdot 7$ & $3 \cdot 1$ & $10 \cdot 7$ & $1 \cdot 8$ & 0.67 & 0.50 & $1 \cdot 18$ \\
\hline Halibut, Atlantic or Pacificł & 3012 & $2 \cdot 9$ & $0 \cdot 4$ & $1 \cdot 0$ & 0.9 & 0.09 & $0 \cdot 37$ & 0.47 \\
\hline White fish (sole, rockfish, haddock, cod, etc.) & & & & & & $0 \cdot 13$ & 0.21 & $0 \cdot 34$ \\
\hline Flatfish (sole or flounder or plaice) $\ddagger$ & 3007 & $1 \cdot 5$ & 0.4 & $0 \cdot 3$ & $0 \cdot 6$ & 0.24 & 0.26 & 0.50 \\
\hline Rockfish, Pacific ocean perch, mixed speciesł & 3044 & $2 \cdot 0$ & 0.5 & $0 \cdot 4$ & $0 \cdot 6$ & $0 \cdot 18$ & $0 \cdot 26$ & 0.44 \\
\hline Haddock $\ddagger$ & 3199 & 0.9 & 0.2 & $0 \cdot 2$ & 0.3 & 0.08 & $0 \cdot 16$ & 0.24 \\
\hline Cod (scrod), Atlantic $\ddagger$ & 3195 & 0.9 & $0 \cdot 2$ & $0 \cdot 1$ & 0.3 & 0.00 & $0 \cdot 15$ & $0 \cdot 16$ \\
\hline Molluscs (mussels, oysters, clams, scallops) & & & & & & 0.24 & 0.25 & 0.49 \\
\hline Molluscs, mussel, bluell & 3116 & $4 \cdot 5$ & 0.9 & $1 \cdot 0$ & $1 \cdot 2$ & 0.28 & 0.51 & $0 \cdot 78$ \\
\hline Molluscs, oyster, Pacific & 3122 & $2 \cdot 3$ & 0.5 & $0 \cdot 4$ & 0.9 & 0.44 & $0 \cdot 25$ & 0.69 \\
\hline Molluscs, clam, mixed species§ & 3112 & $2 \cdot 0$ & $0 \cdot 2$ & $0 \cdot 2$ & 0.6 & $0 \cdot 14$ & $0 \cdot 15$ & 0.28 \\
\hline Molluscs, scallop, mixed species & 3213 & $0 \cdot 8$ & $0 \cdot 1$ & $0 \cdot 0$ & $0 \cdot 3$ & 0.09 & $0 \cdot 11$ & $0 \cdot 20$ \\
\hline Crustaceans (shrimps, crabs, lobsters, etc.) & & & & & & $0 \cdot 19$ & $0 \cdot 11$ & $0 \cdot 29$ \\
\hline Shrimp, mixed species\| & 3212 & $1 \cdot 1$ & $0 \cdot 3$ & 0.2 & 0.4 & $0 \cdot 17$ & $0 \cdot 14$ & 0.32 \\
\hline Crab, Atlantic snow crab (spider, queen)\| & 3173 & $1 \cdot 5$ & $0 \cdot 2$ & $0 \cdot 3$ & 0.5 & 0.33 & $0 \cdot 15$ & 0.48 \\
\hline Lobster, American (northern)\| & 3210 & 0.6 & $0 \cdot 1$ & $0 \cdot 2$ & $0 \cdot 1$ & 0.05 & 0.03 & 0.08 \\
\hline \multicolumn{9}{|l|}{ Imitation crab } \\
\hline Crab, Alaska king, imitation (surimi) & 3095 & $1 \cdot 3$ & $0 \cdot 3$ & $0 \cdot 2$ & $0 \cdot 7$ & $0 \cdot 24$ & $0 \cdot 36$ & 0.61 \\
\hline
\end{tabular}

Italic numbers represent the mean of EPA and DHA values of each species included in this category. The foods were obtained by an online search for foods in the Canadian Nutrient File, version 2007b (http://www.hc-sc.gc.ca/fn-an/nutrition/fiche-nutri-data/index_e.html; accessed April 2008).

‡Baked or broiled.

§Canned.

IIBoiled or steamed.

TRaw. 